\title{
Effect of pretransplant depression on neutrophil recovery following hematopoietic stem cell transplantation
}

This article was published in the following Dove Press journal:

Transplant Research and Risk Management

\author{
Maria Tavakoli-Ardakani ${ }^{1,2}$ \\ Narges Beyraghi ${ }^{3}$ \\ Mahtabalsadat Mirjalili ${ }^{4}$ \\ Ehsan Mirzaei ${ }^{4}$ \\ Maryam Mehrpooya ${ }^{5}$ \\ 'Department of Clinical Pharmacy, \\ School of Pharmacy, Shahid Beheshti \\ University of Medical Sciences, Tehran, \\ Iran; ${ }^{2}$ Pharmaceutical Sciences Research \\ Center, Shahid Beheshti University of \\ Medical Sciences, Tehran, Iran; \\ ${ }^{3}$ Neurofunctional and Neurology \\ Research Center, Shahid Beheshti \\ University of Medical Sciences, Tehran, \\ Iran; ${ }^{4}$ Department of Clinical Pharmacy, \\ School of Pharmacy, Shiraz University of \\ Medical Sciences, Shiraz, Iran; \\ ${ }^{5}$ Department of Clinical Pharmacy, \\ School of Pharmacy, Hamadan University \\ of Medical Sciences, Hamadan, Iran
}

Purpose: Pre-transplantation depression is known to exert negative effects on clinical outcomes after hematopoietic stem cell transplantation (HSCT). Accumulating evidence shows a bidirectional association between inflammation and depression. Systemic inflammation can affect clinical outcomes after transplantation, such as time to engraftment. This study evaluated the effect of pre-transplantation depression and serum level of proinflammatory and anti-inflammatory cytokines on clinical outcomes such as neutrophil recovery time and mortality in patients undergoing HSCT.

Patients and methods: In this cross-sectional study, we recruited 73 patients who were autologous or allogeneic HSCT candidates. Hospital Anxiety and Depression Scale questionnaire was used to assess depression in the first 2 days after their hospital admission. Serum levels of IL-10, IL-6, and hs-CRP were measured at the same time. Neutrophil engraftment time, length of hospitalization, rate of mortality, relapses, readmissions, and occurrence of major complications following HSCT in a 1-year follow-up period were recorded as comparative outcomes.

Results: Thirty-five patients with depression and 38 patients without depression participated in the study. Among the related outcomes, time of engraftment $(P=0.020)$ and mortality rate $(P=0.059)$ were statistically different between the two groups. Depressed patients had longer neutrophil engraftment time and higher mortality rate 1 year following transplantation $(14.14 \pm 3.95$ days and $31.43 \%)$ in comparison to non-depressed patients $(12.21 \pm 2.81$ days and $13.16 \%$ ). Depressed patients showed significantly higher serum levels of IL-6 and IL-6-to-IL-10 ratio compared to non-depressed participants $(P<0.001$ and $P=0.004)$.

Conclusion: According to the results, pre-transplant depression can negatively impact neutrophil recovery time and mortality rate following HSCT. Higher levels of inflammatory factors in depressed patients might be one of the mechanisms that negatively affect clinical outcomes after HSCT.

Keywords: depression, inflammation, hematopoietic stem cell transplantation, neutrophil recovery time

\section{Introduction}

Hematopoietic stem cell transplantation (HSCT) is a life-saving medical procedure for treatment of several malignant and non-malignant hematologic and nonhematologic disorders, including lymphomas, acute and chronic leukemias, aplastic anemia, multiple myeloma, neuroblastoma, some solid tumors, severe combined immunodeficiency, inherited immune disorders, and myelodysplastic syndromes.
Correspondence: Maryam Mehrpooya Department of Clinical Pharmacy, School of Pharmacy, Hamadan University of Medical Sciences, Shahid Fahmideh Ave, Hamadan 65I7838678, Iran

Tel +9 88| 3821868

Fax +9808138381591

Email m_mehrpooya2003@yahoo.com 
Depending on the stem cell donor, "self" versus "non-self", HSCT is divided into two subcategories: autologous and allogeneic. ${ }^{1}$ In this procedure, stem cells collected from peripheral blood, bone marrow, or umbilical cord blood are infused into a patient who is in an intensive condition. ${ }^{2}$ HSCT is identified as a risky treatment, and the high rate of morbidity and mortality following HSCT is a concerning issue. ${ }^{3}$ It is estimated that 2-year allogeneic transplant-related mortality is $6 \%-51 \%$, depending on various factors, such as pre-transplant disease status and comorbidities. ${ }^{4}$ Also, it was reported that approximately $40 \%-70 \%$ of patients undergoing autologous transplant experience relapses. ${ }^{5}$

Patient outcomes following HSCT depend on a variety of factors, including the recipient's demographic characteristics, transplant type, underlying disease and its stage, preparative regimens (myeloablative versus nonmyeloablative), stem cell source, and human leukocyte antigen disparity in allogeneic HSCT. ${ }^{6,7}$ In recent years, a growing number of studies have emphasized the role of psychosocial status as a risk or protective factor for shortand long-term HSCT outcomes. ${ }^{3}$ A review by Hoodin et al showed that negative emotional status pre-transplant was associated with poor long-term survival, while pretransplant optimism had a positive impact on short-term survival. Depression was identified as the most frequently identified risk factor among all the negative and positive emotional profiles and appeared to have the most important effect on early post-HSCT mortality. ${ }^{8}$

The mechanism by which depression affects postHSCT outcomes has not been clearly defined, but it is assumed that depressed patients pay less attention to their care, adhere poorly to treatment regimens, have less access to health services, have poor health behaviors such as poor diet, inappropriate sleep, lack of physical activity, drug abuse, and smoking. ${ }^{9,10}$ In addition to indirect effects of these maladaptive behavioral factors, there are several evidences regarding the negative effects of psychological status, including depression, on immune recovery and functions as well as the subsequent clinical outcomes. ${ }^{11-13}$

A growing body of evidence in recent years shows that systemic inflammation plays an important role in the pathogenesis of depression. ${ }^{14-16}$ It was reported that patients with depression have higher blood levels of pro-inflammatory cytokines, such as CRP, TNF- $\alpha$, IL-1, IL-6, and IL-2R in comparison with non-depressed patients. ${ }^{17-19}$ In addition, activation of local and systemic inflammation in patients undergoing HSCT can negatively impact clinical outcomes after transplantation. ${ }^{20}$ Several studies have shown that the occurrence of some major HSCT-related complications can be the consequence of systemic inflammatory response syndrome. $^{21}$ Increased serum level of some proinflammatory cytokines was also observed during such complications after transplantation. ${ }^{22}$

In Iran, the incidence of transplantable diseases is relatively high, reaching 1,400 patients per year. ${ }^{23}$ It was reported that a total of 3,170 HSCTs were carried out since the establishment of transplantation centers in Iran within the past 20 years, and the rates are increasing annually. ${ }^{24}$ Preventive approaches to post-HSCT complications will reduce health care costs and improve patients' quality of life and life expectancy. Considering all of this, we aimed to evaluate whether patients with pre-transplantation depression require a longer time for neutrophil recovery, and whether they will have different outcomes such as length of hospitalization, mortality, readmission, and relapse 1 year after transplantation, in comparison with patients without depression. We also investigated the association between depression and serum levels of pro-inflammatory cytokines (IL-6 and hs-CRP) and anti-inflammatory cytokine (IL-10) in patients undergoing $\mathrm{HSCT}$ as a probable pathologic pathway that can adversely affect clinical outcomes after transplantation.

\section{Material and methods}

\section{The study population}

This cross-sectional study was conducted at the HSCT center of Taleghani Hospital, affiliated with Shahid Beheshti Medical University (SBMU), Tehran, Iran, from July 2015 until August 2017. The study protocol was approved by the Research Ethics Committee of SBMU. All participants were informed about the study objectives, and had signed an informed consent. This study was conducted in accordance with the Helsinki Declaration.

Candidates for autologous or allogeneic HSCT aged 18-60 years old admitted to the Bone Marrow Transplant Center, were enrolled in the study. The patients with documented hepatic or kidney dysfunction, active infection, autoimmune diseases, severe and/or uncontrolled mental illness or cognitive dysfunction, history of receiving anti-depressants, anti-anxiety, immunosuppressive and/or anti-inflammatory agents within the last month prior to the study were excluded. 


\section{Depression assessment}

During the first 48 hours after admission to the Transplantation ward, a psychiatric assessment was done for all participants, depression was diagnosed by a psychiatrist and the severity of depression was determined using Hospital Anxiety and Depression Scale (HADS) questionnaire, and accordingly, the participants were categorized into two subgroups: patients with and without pre-transplantation depression.

The participants' demographic and clinical data including age, sex, body mass index (BMI), marital status, education level, diseases leading to transplantation, stage of the disease at transplantation time, HSCT type (autologous or allogeneic), conditioning regimen (myeloablative/nonmyeloablative), and stem cell source were recorded by the researcher.

The HADS questionnaire was utilized to evaluate the depression before transplantation. The Persian version of the questionnaire was previously validated among Iranian population by Montazeri et al, 2003. ${ }^{25}$ Participants completed the questionnaire independently, and information and assistance was provided by the research team if needed.

HADS consists of seven questions for anxiety and seven questions for depression. Each item is composed of a 3-point scale (from 0-3 scores). The total score for depression severity is the sum of seven items with a cutoff of $\geq 8$ for depression. The minimum total HADS score is 0 (no depression) and the maximum score is 21 (maximal depression). Participants with a HADS score $\geq 8$ are considered depressed.

\section{Inflammatory cytokine serum levels}

To measure the serum levels of inflammatory cytokines, $5 \mathrm{~mL}$ blood samples were collected during the first 48 hours after admission, and samples were centrifuged for 10 minutes within a few hours. Serum was removed, frozen, and kept at $-70^{\circ} \mathrm{C}$ until further analysis. The concentrations of hs-CRP, IL-6, and IL-10 were measured using high-sensitivity sandwich ELISA kits (Immulite, DPC Cirrus Inc., Los Angeles, CA, USA; Amersham Bioscience, USA; and Bender Med Systems, Austria, respectively).

\section{Outcome assessment}

Patients were followed-up for a year, with regular appointments every 2-4 weeks. The length of hospitalization during transplantation, the occurrence of major post- transplantation adverse outcomes (such as infection, graftversus-host disease [GVHD], veno-occlusive disease, renal and liver dysfunction), relapses, readmissions, rate and reason for mortality were recorded for each patient.

Time to neutrophil engraftment was also documented and was defined as absolute neutrophil count $>500 / \mu \mathrm{L}$ for 3 consecutive days.

\section{Statistical analysis}

All data were analyzed using the statistical package for social sciences (SPSS) version 20 for windows (SPSS Inc., Chicago, IL, USA). The normality of the variables' distributions was checked using Kolmogorov-Smirnov test. Mean \pm SD and median (interquartile range) were used for normally and non-normally distributed continuous variables, respectively. Categorical variables were presented as absolute and relative (percentage) frequencies.

The independent samples t-test and Mann-Whitney $\mathrm{U}$ test were used to compare normally and non-normally distributed continuous parameters between the two groups. Also, the distribution of categorical variables between the two groups was compared using chi-squared or Fisher's exact test (if more than $20 \%$ of the categories had expected frequencies $<5$ ). $P$-values $<0.05$ were considered to be statistically significant.

\section{Results}

Ninety-six patients were screened for recruitment. Fifteen patients did not meet the inclusion criteria, and eight patients did not agree to parcipitate in the study. Finally, related data of 73 participants including 35 and 38 patients with or without depression respectively, were collected and analyzed.

The participants' demographic and relevant clinical information is shown in Table 1. No statistically significant difference was found between the two groups regarding their clinical and demographic characteristics. The mean (SD) baseline HADS scores of patients with and without depression were 11.74 (2.55) versus 3.25 (2.06), respectively. The most common disease leading to transplantation was non-Hodgkin lymphoma; $71.23 \%$ of patients (52 patients) received autologous HSCT and $28.77 \%$ of patients (21 patients) received allogenous HSCT. Regarding the outcomes after transplantation, only time to neutrophil engraftment and mortality rate were statistically different between the two groups ( $P=0.020$ and $P=0.059$ respectively). Patients with depression had a longer time to neutrophil recovery $(14.14 \pm 3.95$ 
Table I Baseline demographics and relevant clinical data of the patients with and without depression

\begin{tabular}{|c|c|c|c|c|}
\hline \multicolumn{2}{|l|}{ Variable } & $\begin{array}{l}\text { Patients with depres- } \\
\text { sion } \\
(\mathbf{N}=35)\end{array}$ & $\begin{array}{l}\text { Patients without depres- } \\
\text { sion } \\
(\mathbf{N}=38)\end{array}$ & $P$-value \\
\hline \multicolumn{2}{|l|}{ Age (years), mean \pm SD } & $40.63 \pm 13.17$ & $40.7 I \pm 14.06$ & 0.98 \\
\hline \multicolumn{2}{|l|}{ BMI (kg/m2), mean \pm SD } & $25.02 \pm 3.74$ & $26.33 \pm 3.41$ & 0.123 \\
\hline \multicolumn{2}{|c|}{ Basal depression score, mean \pm SD } & $1 \mathrm{I} .74 \pm 2.55$ & $3.29 \pm 2.06$ & $<0.001$ \\
\hline Sex, N (\%) & $\begin{array}{l}\text { Male } \\
\text { Female }\end{array}$ & $\begin{array}{l}14(40 \%) \\
21(60 \%)\end{array}$ & $\begin{array}{l}19(50 \%) \\
19(50 \%)\end{array}$ & 0.391 \\
\hline Marital status, N (\%) & $\begin{array}{l}\text { Single } \\
\text { Married }\end{array}$ & $\begin{array}{l}6(17.14 \%) \\
29(82.86 \%)\end{array}$ & $\begin{array}{l}7(18.42 \%) \\
31(81.58 \%)\end{array}$ & 0.887 \\
\hline Level of education, $\mathbf{N}$ (\%) & $\begin{array}{l}\text { Below high school } \\
\text { High school } \\
\text { Above high school }\end{array}$ & $\begin{array}{l}7(20.0 \%) \\
20(57.14 \%) \\
8(22.86 \%)\end{array}$ & $\begin{array}{l}12(31.58 \%) \\
16(42.11 \%) \\
10(26.32 \%)\end{array}$ & 0.394 \\
\hline Type of disease, $\mathbf{N}(\%)$ & $\begin{array}{l}\text { AML } \\
\text { ALL } \\
\text { MM } \\
\mathrm{NHL} \\
\mathrm{HL} \\
\text { Testicular germ cell tumor }\end{array}$ & $\begin{array}{l}5(14.29 \%) \\
8(22.86 \%) \\
6(17.14 \%) \\
9(25.71 \%) \\
6(17.14 \%) \\
1(2.86 \%)\end{array}$ & $\begin{array}{l}6(15.79 \%) \\
3(7.89 \%) \\
8(21.05 \%) \\
12(31.58 \%) \\
8(21.05 \%) \\
1(2.63 \%)\end{array}$ & 0.662 \\
\hline Stage of disease, $\mathbf{N}(\%)$ & $\begin{array}{l}\text { PR } \\
\text { GPR } \\
\text { VGPR } \\
\text { CR }\end{array}$ & $\begin{array}{l}12(34.29 \%) \\
5(14.29 \%) \\
4(11.43 \%) \\
14(40.0 \%)\end{array}$ & $\begin{array}{l}14(36.84 \%) \\
9(23.68 \%) \\
2(5.26 \%) \\
13(34.21 \%)\end{array}$ & 0.598 \\
\hline Type of transplantation, $\mathbf{N}(\%)$ & $\begin{array}{l}\text { Allogenous } \\
\text { Autologous }\end{array}$ & $\begin{array}{l}12(34.29 \%) \\
23(65.71 \%)\end{array}$ & $\begin{array}{l}9(23.68 \%) \\
29(76.32 \%)\end{array}$ & 0.317 \\
\hline Conditioning regimen, $\mathbf{N}(\%)$ & $\begin{array}{l}\text { Myeloablative } \\
\text { Non-myeloablative }\end{array}$ & $\begin{array}{l}30(85.71 \%) \\
5(14.29 \%)\end{array}$ & $\begin{array}{l}32(84.21 \%) \\
6(15.79)\end{array}$ & 0.858 \\
\hline Stem cell source, $\mathbf{N}(\%)$ & Peripheral blood & $35(100 \%)$ & $38(100 \%)$ & 0.225 \\
\hline
\end{tabular}

Notes: The bold data indicates the significance was 0.000 in the SPSS, which is usually shown as $<0.001$ in the articles.

Abbreviations: BMI, body mass index; AML, acute myelogenous leukemia; ALL, acute lymphocytic leukemia; MM, multiple myeloma; NHL, non-Hodgkin lymphoma; HL, Hodgkin lymphoma; PR, partial remission; GPR, good partial remission; VGPR, very good partial remission; CR, complete remission.

versus $12.21 \pm 2.81$ days) and higher mortality rate $(31.43 \%$ versus $13.16 \%)$. Analysis of other outcomes showed that non-depressed patients had shorter hospital stay, as well as lower rate of complications and adverse outcomes, relapses, and readmissions during the 1-year follow-up post-transplantation in comparison to depressed patients, but these differences were not statistically significant (Table 2).

Comparison of inflammatory and anti-inflammatory cytokines showed that patients with pre-transplantation depression had significantly higher concentrations of IL-6 and IL-6-to-IL-10 ratios ( $P<0.001$ and $P=0.004)$. Although IL-10 and hs-CRP serum levels were higher in depressed patients in comparison with non-depressed patients, it did not reach statistical significance $(P=0.821$ and $P=0.145$ respectively) (Table 3).

\section{Discussion}

In this cross-sectional study, we presented the clinical outcomes of 35 depressed and 38 non-depressed patients who underwent HSCT at a single center, which is one of the major referral centers for HSCT in Iran, from 2015 until 2017. The main findings showed that non-depressed patients achieved better outcomes following HSCT, especially regarding time to neutrophil engraftment and mortality rate. 
Table 2 Comparison of outcome after HSCT in patients with and without depression

\begin{tabular}{|c|c|c|c|}
\hline Variable & $\begin{array}{l}\text { Patients with depres- } \\
\text { sion } \\
(\mathrm{N}=35)\end{array}$ & $\begin{array}{l}\text { Patients without depres- } \\
\text { sion } \\
(\mathbf{N}=38)\end{array}$ & $P$-value \\
\hline Time to engraftment, mean \pm SD & $14.14 \pm 3.95$ & $|2.2| \pm 2.8 \mid$ & 0.020 \\
\hline In-hospital duration, mean \pm SD & $29.66 \pm 8.82$ & $27.34 \pm 6.29$ & 0.198 \\
\hline Mortality during I year post-transplantation, N (\%) & II (3I.43\%) & $5(13.16 \%)$ & 0.059 \\
\hline \multicolumn{4}{|l|}{ Mortality reason, $\mathbf{N}(\%)$} \\
\hline Relapse & $6(17.14 \%)$ & $2(5.26 \%)$ & 0.590 \\
\hline Infection & $4(14.29 \%)$ & $3(7.89 \%)$ & \\
\hline GVHD & $\mathrm{I}(2.85 \%)$ & $0(0 \%)$ & \\
\hline Complication during I year post-transplantation, $\mathbf{N}(\%)$ & $13(37.14 \%)$ & $9(23.68 \%)$ & 0.211 \\
\hline Readmission during I year post-transplantation, $\mathbf{N}(\%)$ & $18(51.43 \%)$ & $12(31.58 \%)$ & 0.085 \\
\hline Relapse during I year post-transplantation, $\mathbf{N}(\%)$ & $8(22.86 \%)$ & $5(13.16 \%)$ & 0.279 \\
\hline
\end{tabular}

Notes: The bold data indicates the significance was 0.000 in the SPSS, which is usually shown as $<0.001$ in the articles.

Abbreviations: $\mathrm{HSCT}$, hematopoietic stem cell transplantation; GVHD, graft-versus-host disease

Table 3 Comparison of inflammatory and anti-inflammatory markers between the two groups

\begin{tabular}{|c|c|c|c|}
\hline Variable & $\begin{array}{l}\text { Patients with depression } \\
(\mathrm{N}=35)\end{array}$ & $\begin{array}{l}\text { Patients without depression } \\
(\mathrm{N}=38)\end{array}$ & $P$-value \\
\hline IL-6, median (IQR) & $243(96-345)$ & $86(65-145)$ & $<0.001$ \\
\hline hs-CRP, median (IQR) & $9(3-22)$ & $5(3-12.25)$ & 0.145 \\
\hline IL-I0, median (IQR) & $73(45-118)$ & $70(47.25-132.25)$ & 0.821 \\
\hline IL-6/IL-I 0 (IQR) & $3.15(1.14-5.44)$ & $1.33(0.79-2.01)$ & 0.004 \\
\hline
\end{tabular}

Notes: The bold data indicates the significance was 0.000 in the SPSS, which is usually shown as $<0.001$ in the articles.

Abbreviation: IQR, interquartile range.

Our findings are in line with those of El-Jawahri et al's study, the largest multicenter study of allogeneic HSCT recipients in which an association between pretransplantation depression and the overall survival rate was evaluated. They concluded that pre-transplantation depression was associated with lower overall survival, a higher incidence of grade 2-4 acute GVHD, fewer days alive and out of the hospital in patients undergoing allogenic HSCT. Also, patients undergoing autologous HSCT with pre-transplantation depression had fewer days alive out of hospital. ${ }^{26}$ In another study, it was shown that patients suffering from depression according to HADS questionnaire, had a relative risk factor for their overall survival following HSCT. In other words, depressed patients (with HADS score $=10$ ) were more than two-and-a-half times more likely than non-depressed patients (with HADS score $=0$ ) to die after $\mathrm{HSCT}^{27}$
Increasing evidence has demonstrated the association between behavioral factors, such as life stress, depression, anxiety, benefit finding, and social support and cancer outcomes including, progression, metastases, recurrence, survival, and quality of life. Although the exact mechanisms are not completely understood, it seems that behavioral and psychosocial factors affect immune, angiogenic, and inflammatory pathways involved in the development, progression, and management of different kinds of tumors and malignancies through activation of neuroendocrine transmitters. ${ }^{13}$ Depression and low level of mood have been associated with poorer prognosis, greater mortality, and reduced survival time in patients undergoing HSCT. ${ }^{8}$ Depressed patients have a greater tendency to engage in health-threatening behaviors such as smoking and alcohol consumption, and show poor compliance to their medication and post-HSCT treatment advice. Additionally, 
depression contributes to impaired immune system function, which has an important role in recovery following HSCT. $^{3,28}$

Our results showed a significant difference between depressed and non-depressed patients regarding neutrophil recovery time. Patients undergoing HSCT experience three phases following transplantation: the pre-engraftment phase or early recovery (from 2-6 weeks after transplantation [it has been shortened to 3 weeks or less since the use of peripheral blood stem cells]), the mid-recovery (the second and third month after transplantation), and the late recovery phase (the interval beyond 3 months). ${ }^{29}$ Bacterial and non-bacterial infections are important challenges after HSCT, especially in the pre-engraftment phase. ${ }^{30}$ One of the main risk factors for infections is the duration of neutropenia; the longer the time to engraftment, the greater the potential for infections. ${ }^{31,32}$ The rate of rehospitalization is higher among patients who experience post-transplant infection. Also, patients are more vulnerable to chronic diarrhea, upset stomach, and severe mouth pain caused by mucositis in the immune deficiency phase. ${ }^{33}$ Prolongation of the immune deficiency period is associated with higher morbidity and mortality. ${ }^{34}$ Thus, the results of this study can have clinical implications for patients undergoing HSCT, by placing emphasis on treating pre-transplant depression and anxiety, which is probably due to reduced neutrophil recovery time, that can lead to reduced morbidity, mortality, and immune deficiency-related problems, such as infection during the post-transplant period.

In several studies the effects of psychosocial factors on time to engraftment were evaluated. Knight et al showed that patients with greater optimism (assessed by the 10item revised version of Life Orientation Test) and less anxiety (assessed by the 20-item State-Trait Anxiety Inventory, Trait version) had a shorter time to engraftment. $^{35}$ In other research, it was concluded that higher levels of pre-treatment depression and anxiety were associated with slower white blood cell recovery in adult autologous HSCT patients during the first 3 weeks after transplantation. ${ }^{33}$ It was claimed that patients with depression before transplantation, had a decreased survival rate in comparison with normal individuals. ${ }^{9,27,36}$

The exact mechanisms involved in psychosocial factors and clinical outcomes after transplantation are still unknown. It seems that psychosocial factors, including depression, anxiety, distress, optimism, etc can influence catecholamines and glucocorticoids' release, as well as inflammation, angiogenesis, and cellular immune function. ${ }^{37}$ Stress can increase catecholamine levels in the body. ${ }^{38}$ On the other hand, catecholamine levels are higher in the bone marrow microenvironment compared to circulation. ${ }^{39}$ Some animal studies have shown that function and capabilities of neutrophils are suppressed in the presence of higher levels of catecholamines. ${ }^{40}$

Inflammation is the key element in the behavioural mechanisms involved in HSCT outcomes. It seems that the relationship between depression and inflammation is likely to be bidirectional. It has been proven that inappropriate psychological and physical conditions, such as stress, depression, obesity, and atherosclerosis can induce inflammation. ${ }^{41}$ On the other hand, inflammation might have a potential role in the development of psychological disorders. $^{42}$ The release of pro-inflammatory cytokines such as, IL-1, IL-6, and TNF- $\alpha$ leads to increased morbidity and mortality, which leads to experiences such as feeling ill, aches and pains, fatigue, disturbed sleep, and poorer quality of life following transplantation. ${ }^{43-45}$ Also, results of the present study are in line with our previous study showing a significantly higher serum level of IL-6 and IL-6-to-IL-10 ratio in depressed patients in comparison with non-depressed ones. ${ }^{19}$ Many studies have focused on the associations between inflammatory markers and depression. In one meta-analysis of 51 studies for CRP, 62 for IL-6, and 14 for IL-1, each inflammatory marker was positively associated with depression. ${ }^{18}$ However, in our study no significant difference was observed regarding hs-CRP serum level between depressed and non-depressed patients. This might be due to the small sample size of our study population in comparison with other studies.

The procedural requirements for HSCT, including conditioning therapy, induce tissue damage and subsequently, inflammation. ${ }^{3}$ The role of inflammatory cytokines has been widely recognized in multiple complications after bone marrow transplantation. Elevated levels of TNF- $\alpha$, IL-1, and a shift toward a $\mathrm{T}$ helper 1 immune response, play an important role in the pathogenesis of GVHD. ${ }^{46,47}$ Also, hs-CRP has been considered as an early predictor of severe post-transplant complications and survival. ${ }^{48}$ Results of several studies have demonstrated that increased levels of IL-1, IL-6, and TNF- $\alpha$ were associated with sickness, as well as poorer quality of life among HSCT survivors. ${ }^{44,45}$ In this regard, in a previous study we showed that treating depression among HSCT patients with sertraline could positively influence engraftment time, readmission, and mortality after transplantation. ${ }^{49}$ 
Growing evidence has shown that treating depressed patients with anti-depressant drugs such as selective serotonin reuptake inhibitors can positively reduce pro-inflammatory markers such as TNF- $\alpha$ and IL- 6 and increase anti-inflammatory cytokines such as IL-4 and IL-10. ${ }^{50}$ At the same time, our data confirm the theory that lack of balance between pro- and anti-inflammatory markers is associated with depression, as depressed HSCT patients have significantly higher levels of IL-6 and IL-6-to-IL-10 ratio compared to non-depressed ones. Consequently, activation of inflammatory pathways might be a mechanism that can negatively affect clinical outcomes such as longer neutrophil recovery time and higher mortality rate in HSCT patients.

There were several limitations in this study, such as the small sample size $(\mathrm{N}=73)$, this might have limited the statistical power and complicates generalization of the study results. Second, the study was conducted at a single center which restricts the generalization of our findings to other institutions or populations of different ethnicities. Third, the number of studied biomarkers were limited and only one sample was taken from each patient at baseline and patients were not followedup after HSCT regarding the blood level of cytokines. Also, the short half-life of the markers, especially IL-6 and CRP, might have caused errors during the study. ${ }^{51}$ Forth, the heterogenicity of the recruited patients regarding the type of disease and its stage, type of HSCT (allogenous or heterogenous), treatment options, and different complications might have interfered with the study's objectives.

\section{Conclusion}

Our findings suggest that pre-transplantation depression can have a negative impact on the neutrophil recovery time, as well as mortality rate in patients undergoing HSCT. Also, a relatively higher level of IL-6 and IL6-to-IL-10 ratio was observed among patients with peritransplant depression, which emphasizes the role of inflammation in the pathogenesis of psychological disorders and its probable effects on the outcomes of transplantation. Thus, patients with pre-transplantation depression could be identified as a vulnerable population with a higher risk of adverse outcomes compared to non-depressed patients and, therefor, special care should be considered in managing their psychological disorders more accurately and appropriately.

\section{Acknowledgments}

This study was supported by the Vice-Chancellor of Research and Technology of Shahid Beheshti University of Medical Sciences, Tehran, Iran. The authors thank all staff of Taleghani Hospital and all patients for helping and participating in the study. The authors wish to thank $\mathrm{Mr}$ $\mathrm{H}$ Argasi at the Research Consultation Center (RCC) of Shiraz University of Medical Sciences for his invaluable assistance in editing this manuscript.

\section{Disclosure}

The authors report no conflicts of interest in this work.

\section{References}

1. Ertas E, Kurnaz F, Zorba Y, et al. Comparison of chemotherapy and hematopoietic stem cell transplantation pre and postterm DMFT scores: a preliminary study. Niger J Clin Pract. 2014;17(1):32-37. doi:10.4103/1119-3077.122831

2. Barrett AJ, Battiwalla M. Relapse after allogeneic stem cell transplantation. Expert Rev Hematol. 2010;3(4):429-441. doi:10.1586/ehm.10.32

3. Costanzo ES, Juckett MB, Coe CL. Biobehavioral influences on recovery following hematopoietic stem cell transplantation. Brain Behav Immun. 2013;30:S68-S74. doi:10.1016/j. bbi.2012.07.005

4. Bacigalupo A, Sormani MP, Lamparelli T, et al. Reducing transplant-related mortality after allogeneic hematopoietic stem cell transplantation. Haematologica. 2004;89(10):1238-1247.

5. Porrata L, Markovic S. Timely reconstitution of immune competence affects clinical outcome following autologous stem cell transplantation. Clin Exp Med. 2004;4(2):78-85.

6. Gratwohl A. Risk assessment in haematopoietic stem cell transplantation. Best Pract Res Clin Haematol. 2007;20(2):119-124. doi:10.1016/j.beha.2006.10.011

7. Appelbaum FR. The use of bone marrow and peripheral blood stem cell transplantation in the treatment of cancer. CA Cancer J Clin. 1996;46(3):142-164.

8. Hoodin F, Uberti J, Lynch T, Steele P, Ratanatharathorn V. Do negative or positive emotions differentially impact mortality after adult stem cell transplant? Bone Marrow Transplant. 2006;38 (4):255. doi:10.1038/sj.bmt.1705419

9. Loberiza FR Jr, Rizzo JD, Bredeson CN, et al. Association of depressive syndrome and early deaths among patients after stem-cell transplantation for malignant diseases. J Clin Oncol. 2002;20(8):2118-2126. doi:10.1200/JCO.2002.08.757

10. Kiecolt-Glaser JK, Glaser R. Methodological issues in behavioral immunology research with humans. Brain Behav Immun. 1988;2 (1):67-78.

11. Kiecolt-Glaser JK, Glaser R. Depression and immune function: central pathways to morbidity and mortality. J Psychosom Res. 2002;53 (4):873-876.

12. Burns EA, Lum LG, Seigneuret MC, Giddings BR, Goodwin JS. Decreased specific antibody synthesis in old adults: decreased potency of antigen-specific B cells with aging. Mech Ageing Dev. 1990;53(3):229-241.

13. Costanzo ES, Sood AK, Lutgendorf SK. Biobehavioral influences on cancer progression. Immunol Allergy Clin North Am. 2011;31 (1):109-132. doi:10.1016/j.iac.2010.09.001 
14. Cavet J, Dickinson AM, Norden J, Taylor PR, Jackson GH, Middleton PG. Interferon- $\gamma$ and interleukin- 6 gene polymorphisms associate with graft-versus-host disease in HLA-matched sibling bone marrow transplantation. Blood. 2001;98(5):1594-1600.

15. Tegg E, Griffiths A, Lowenthal R, et al. Association between high interleukin-6 levels and adverse outcome after autologous haemopoietic stem cell transplantation. Bone Marrow Transplant. 2001;28 (10):929. doi:10.1038/sj.bmt. 1703272

16. Moylan S, Maes M, Wray N, Berk M. The neuroprogressive nature of major depressive disorder: pathways to disease evolution and resistance, and therapeutic implications. Mol Psychiatry. 2013;18(5):595. doi: $10.1038 / \mathrm{mp} .2012 .33$

17. Dowlati Y, Herrmann N, Swardfager W, et al. A meta-analysis of cytokines in major depression. Biol Psychiatry. 2010;67(5):446-457. doi:10.1016/j.biopsych.2009.09.033

18. Howren MB, Lamkin DM, Suls J. Associations of depression with C-reactive protein, IL-1, and IL-6: a meta-analysis. Psychosom Med. 2009;71(2):171-186. doi:10.1097/PSY.0b013e3181907c1b

19. Tavakoli-Ardakani M, Mehrpooya M, Mehdizadeh M, Hajifathali A, Abdolahi A. Association between Interlukin-6 (IL-6), Interlukin-10 (IL-10) and depression in patients undergoing hematopoietic stem cell transplantation. Int J Hematol Oncol Stem Cell Res. 2015;9 (2):80

20. Hill GR. Inflammation and bone marrow transplantation. Biol Blood Marrow Transplant. 2009;15(1):139-141. doi:10.1016/j.bbmt.2008. 11.008

21. Takatsuka H, Takemoto Y, Yamada S, et al. Complications after bone marrow transplantation are manifestations of systemic inflammatory response syndrome. Bone Marrow Transplant. 2000;26(4):419. doi:10.1038/sj.bmt. 1702517

22. Sjøqvist C, Snarski E. Inflammatory markers in patients after hematopoietic stem cell transplantation. Arch Immunol Ther Exp (Warsz). 2013;61(4):301-307. doi:10.1007/s00005-013-0228-z

23. Ghavamzadeh A, Alimoghaddam K, Ghaffari F, Derakhshandeh R, Jalali A, Jahani M. Twenty years of experience on stem cell transplantation in Iran. Iran Red Crescent Med J. 2013;15(2):93. doi:10.5812/ircmj. 1915

24. Ghavamzadeh A, Alimoghaddam K, Jahani M, et al. Stem cell transplantation; Iranian experience. Arch Iran Med. 2009;12 (1):69-72.

25. Montazeri A, Vahdaninia M, Ebrahimi M, Jarvandi S. The hospital anxiety and depression scale (HADS): translation and validation study of the Iranian version. Health Qual Life Outcomes. 2003;1 (1):14. doi:10.1186/1477-7525-1-14

26. El-Jawahri A, Chen YB, Brazauskas R, et al. Impact of pre-transplant depression on outcomes of allogeneic and autologous hematopoietic stem cell transplantation. Cancer. 2017;123(10):1828-1838. doi:10.1002/cncr.30546

27. Grulke N, Larbig W, Kächele H, Bailer H. Pre-transplant depression as risk factor for survival of patients undergoing allogeneic haematopoietic stem cell transplantation. Psycho-Oncology. 2008;17 (5):480-487. doi:10.1002/(ISSN)1099-1611

28. Ehlers SL, Gastineau DA, Patten CA, et al. The impact of smoking on outcomes among patients undergoing hematopoietic SCT for the treatment of acute leukemia. Bone Marrow Transplant. 2011;46 (2):285. doi:10.1038/bmt.2010.113

29. De Bock R, Middelheim A. Febrile neutropenia in allogeneic transplantation. Int J Antimicrob Agents. 2000;16(2):177-180.

30. Omrani AS, Almaghrabi RS. Complications of hematopoietic stem cell transplantation: bacterial infections. Hematol Oncol Stem Cell Ther. 2017;10(4):228-232. doi:10.1016/j.hemonc.2017.05.018

31. Saito T, Kanda Y, Nakai K, et al. Immune reconstitution following reduced-intensity transplantation with cladribine, busulfan, and antithymocyte globulin: serial comparison with conventional myeloablative transplantation. Bone Marrow Transplant. 2003;32(6):601. doi:10.1038/sj.bmt.1704205
32. Mikulska M, Raiola AM, Galaverna F, et al. Pre-engraftment bloodstream infections after allogeneic hematopoietic cell transplantation: impact of $\mathrm{t}$ cell-replete transplantation from a haploidentical donor. Biol Blood Marrow Transplant. 2018;24(1):109-118. doi:10.1016/j. bbmt.2017.08.024

33. McGregor BA, Syrjala KL, Dolan ED, Langer SL, Redman M. The effect of pre-transplant distress on immune reconstitution among adult autologous hematopoietic cell transplantation patients. Brain Behav Immun. 2013;30:S142-S148. doi:10.1016/j.bbi.2012.07.020

34. Peggs KS, Mackinnon S. Immune reconstitution following haematopoietic stem cell transplantation. $B r \quad J$ Haematol. 2004;124 (4):407-420.

35. Knight JM, Moynihan JA, Lyness JM, et al. Peri-transplant psychosocial factors and neutrophil recovery following hematopoietic stem cell transplantation. PLoS One. 2014;9(6):e99778. doi:10.1371/journal.pone. 0099778

36. Andrykowski MA, Brady MJ, Henslee-Downey PJ. Psychosocial factors predictive of survival after allogeneic bone marrow transplantation for leukemia. Psychosom Med. 1994;56(5):432-439.

37. Knight JM, Lyness JM, Sahler OJZ, Liesveld JL, Moynihan JA. Psychosocial factors and hematopoietic stem cell transplantation: potential biobehavioral pathways. Psychoneuroendocrinology. 2013;38(11):2383-2393. doi:10.1016/j.psyneuen.2013.06.016

38. Cole SW, Sood AK. Molecular pathways: beta-adrenergic signaling in cancer. Clin Cancer Res. 2012;18(5):1201-1206. doi:10.1158/ 1078-0432.CCR-11-0641

39. Maestroni GJ. Neurohormones and catecholamines as functional components of the bone marrow microenvironment. Ann $N$ Y Acad Sci. 2000;917(1):29-37.

40. Barker LA, Dazin PF, Levine JD, Green PG. Sympathoadrenaldependent sexually dimorphic effect of nonhabituating stress on in vivo neutrophil recruitment in the rat. Br J Pharmacol. 2005;145 (7):872-879. doi:10.1038/sj.bjp.0706257

41. Elenkov IJ, Iezzoni DG, Daly A, Harris AG, Chrousos GP. Cytokine dysregulation, inflammation and well-being. Neuroimmunomodulation. 2005;12(5):255-269. doi:10.1159/000087104

42. Miller AH, Ancoli-Israel S, Bower JE, Capuron L, Irwin MR. Neuroendocrine-immune mechanisms of behavioral comorbidities in patients with cancer. J Clin Oncol. 2008;26(6):971. doi:10.1200/ JCO.2007.15.2777

43. Wang XS, Shi Q, Williams LA, et al. Serum interleukin-6 predicts the development of multiple symptoms at nadir of allogeneic hematopoietic stem cell transplantation. Cancer. 2008;113(8):2102-2109. doi: $10.1002 /$ cncr.23820

44. Dantzer R, O'Connor JC, Freund GG, Johnson RW, Kelley KW. From inflammation to sickness and depression: when the immune system subjugates the brain. Nat Rev Neurosci. 2008;9(1):46. doi:10.1038/nrn2297

45. Andrykowski MA, Bishop MM, Hahn EA, et al. Long-term health-related quality of life, growth, and spiritual well-being after hematopoietic stem-cell transplantation. J Clin Oncol. 2005;23 (3):599-608. doi:10.1200/JCO.2005.03.189

46. Brunoni AR, Machado-Vieira R, Sampaio-Junior B, et al. Plasma levels of soluble TNF receptors 1 and 2 after tDCS and sertraline treatment in major depression: results from the SELECT-TDCS trial. J Affect Disord. 2015;185:209-213. doi:10.1016/j.jad.2015.07.006

47. El-Jawahri A, Chen Y-B. Pleiotropic approach to graft-versus-host disease. J Clin Oncol. 2013;31(35):4462. doi:10.1200/JCO.2013.49.0219

48. Artz AS, Wickrema A, Dinner S, et al. Pretreatment C-reactive protein is a predictor for outcomes after reduced-intensity allogeneic hematopoietic cell transplantation. Biol Blood Marrow Transplant. 2008;14(11):1209-1216. doi:10.1016/j.bbmt.2008.08.004

49. Tavakoli-Ardakani M, Kheshti R, Maryam M. Effect of sertraline on complications and survival after hematopoietic stem-cell transplantation, a double-blind, placebo-controlled clinical study. Int $J$ Hematol. 2017;106(6):832-841. doi:10.1007/s12185-017-2309-y 
50. Sutcigil L, Oktenli C, Musabak U, et al. Pro-and anti-inflammatory cytokine balance in major depression: effect of sertraline therapy. Clin Dev Immunol. 2008;2007:6.
51. Valkanova V, Ebmeier KP, Allan CL. CRP, IL-6 and depression: a systematic review and meta-analysis of longitudinal studies. J Affect Disord. 2013;150(3):736-744. doi:10.1016/j.jad.2013.06.004

\section{Publish your work in this journal}

Transplant Research and Risk Management is an international, peer-reviewed open access journal focusing on all aspects of transplantation and risk management to achieve optimal outcomes in the recipient improving survival and quality of life. The manuscript management system is completely online and includes a very quick and fair peer-review system, which is all easy to use. Visit http:// www.dovepress.com/testimonials.php to read real quotes from published authors.

Submit your manuscript here: https://www.dovepress.com/transplant-research-and-risk-management-journal 